\title{
Functional Literacy Skills and Problem Solving Skills in Culinary Vocational School
}

\author{
Nunung Nurjanah, Sonhadji, Waras Kamdi \\ Program Doktor Pendidikan Kejuruan \\ Universitas Negeri Malang \\ Malang, Indonesia \\ nunung.nurjanah.ft@um.ac.id
}

\author{
Luthfiyah Nurlaela \\ Department of Home Economics \\ Universitas Negeri Surabaya \\ Surabaya, Indonesia
}

\begin{abstract}
Culinary work is related to services that require adequate interpersonal skills. Vocational Culinary School level operators must have high technical skills, intermediate interpersonal, and low concept. The purpose of this study aims to analyze the skills of vocational aspects of functional literacy and problem solving with culinary expertise. Experiments The population of this study analyzed data from 327 students of vocational culinary school in Malang Raya analyzed using regression. The significance value of 0.000 <alpha 0.05 which means functional literacy variables, and problem solving simultaneously affect on culinary expertise. $R$ square 0,327 , it means functional literacy, and problem solving effect on culinary skill of $32,7 \%$, and $67,3 \%$ influenced by anoother factor. Functional literacy as a generic skill in culinary expertise related to basic culinary concepts that read recipes, prescription interpretations include ingredients and ways of processing and serving food.Vocational students of culinary need to have problem solving ability as stock in work world besides basic knowledge, technique and skill of hand to cook in order to survive in industry
\end{abstract}

Keywords—functional literacy skills; problem solving; culinary expertise

\section{INTRODUCTION}

Culinary is a skill competency under the culinary expertise studies program, tourism category. Culinary skills competencies is the knowledge and skills in the field of processing, serving food and beverages services. The competence of the catering expertise prepares students to work in the field of work managed by travel agencies or institutions, hotels, restaurants, catering and hospitals, and prepare learners to become entrepreneurs in the field of food supply business. There is a change in the terms of tourism by spectrum [1] Directorate of Vocational High School (2016): Expertise: Tourism, Skill Program: Culinary, Skill Competency. The objective of the culinary skill program as stated in the contents of the National Education System Act (UU SPN) article 3 on National Education Objectives and the elucidation of article 15 which states that vocational education is secondary education that prepares students primarily to work in a particular field. Specifically, the purpose of the culinary skill program is to equip learners with the skills, knowledge and attitudes to be competent: 1) Process and serve a continental meal consisting of appetizers, main meals and desserts; 2) Processing and serving Indonesian food consisting of appetizers, staple foods, side dishes and desserts; 3) Serving meals and drinks at restaurants and in hotels, as well as arranging a dining table and buffet table; 4) Processing and serving non-alcoholic drinks; and 5) Organizing food and drink service operations in, restaurants (Directorate of PSMK). According to ([2] vocational education is designed to enable learners to be able to develop the practical skills, knowledge and understanding necessary for a job in a particular field. Skill categories according to [3] required in various sectors include categories of vocational and technical skills, skills as follows

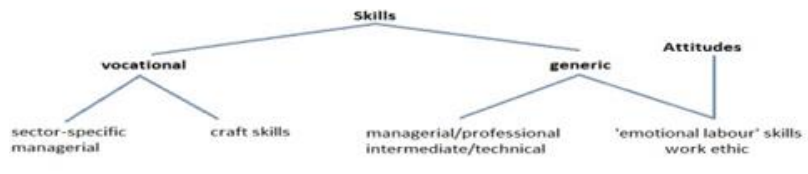

Fig.1. Category of Skills

Both traditional and professional cooking skills were previously seen as low, but in recent years there has been a shift in status. Professionals develop gastronomy by involving different traditional gastronomic staff and opportunities to work. The restaurant as a internship partner is a place of education and training for students to learn and work with cooks. The training or apprenticeship of an expert is based on a new form of knowledge and reflective learning process than traditional learning according to [4]

\section{METHOD}

This research is an explanatory survey method. The population in this study are all students of Culinary vocational school at SMK Hidayatul Mubtadi'in, SMK Kartika IV-1 Malang, SMK Muhammadiyah Singosari, SMK N 1 Batu, SMK N 3 Malang, SMK N 3 Turen, and SMK N 7 who have implemented Practice Industrial Work. The sampling technique used was purposive sampling with the sample of 327 respondents. The instruments used in this study were a Guttman-scale questionnaire for functional literacy questionnaires, and a Likert scale for problemsolving questionnaires and culinary skills. The instrument is tested for validity using Pearson product moment correlation and reliability using alpha cronbach, to then do the data retrieval. 
The data have been taken, first tested classical assumptions include test normality, multicollinearity, and heteroscedasticity. Normality test using Kolmogorov-Smirnov Test with the provision if the significance value> alpha 0.05 then the data is normally distributed, multicollinearity test using the Variance Inflation Factor and Tolerance test, provided that the tolerance value $\geq 10$ and or equal to VIF $<10$ then it can be concluded did not occur multicollinearity. Heteroskedasticity test can be seen by Glejser test, if significance value> 0,05 hence no heteroskedastisitas. Data that has passed the classical assumption test followed by multiple regression analysis.

\section{RESULTS AND DISCUSSIONS}

\section{A.Results}

\section{1) Classic Assumption Test}

Normality test is used to test whether in a regression model the dependent variable, independent or both have a normal distribution or not. Normality test was performed by using Kolmogorov-Smirnov Test. The result of normality test. functional functional significance value of $0.847>0.05$, problem solving of $0.630>0.05$, culinary expertise of $0.170>0.05$, so it can be concluded that the data used in this study normal distribution which means meet the assumption of normality and feasible to use.

Multicollinearity test aims to test whether the regression model found a correlation between independent variables, while a good regression is that there is no correlation between independent variables. The result of multicollinearity test tolerance value $\geq 0.10$ or equal to VIF $<10$ then it can be concluded that there is no multicollinearity.

The heteroscedasticity test is intended to test whether there is any inequality of data from one observation to another. Heteroskedasticity test can be seen with Glejser test, if significance value $\geq 0.05$ then no heteroscedasticity.

The significance value of problem solving of $0.498>0.05$, so it can be concluded that the data used in this study does not occur heteroskedastisitas, meaning meet the assumption of heteroscedasticity and feasible to use

2) Functional Literacy Skill, Problem Solving in Culinary Expertise

Based analysis shows that the value of functional literacy significance with problem solving is $0.590>$ aplha 0.05 , it shows that there is no significant relationship between functional literacy and problem solving. The significance value of functional literacy with culinary expertise is 0.691> aplha 0.05, it shows that there is no significant relationship between functional literacy and culinary expertise. Can be seen the significance value of $0.000<$ alpha 0.05 which means functional literacy variables, and problem solving effect simultaneously (together) on culinary skills. The value of $\mathrm{R}$ square 0,327 , it means functional literacy, and problem solving effect on culinary skill of $32,7 \%$, and $67,3 \%$ influenced by other factor.

3) Effect of Functional Literacy on Culinary Expertise, and Problem Solving to Culinary Expertise
Table coefficients shows the results of multiple linear regression analysis is the value for functional literation variable of -0.164 , and problem-solving variables of 0.687 . So if it is included in the regression formula as a whole, then the equation as follows.

$$
\mathrm{Y}=(-0.164) \mathrm{X} 1+(0.687) \mathrm{X} 2
$$

The value of the functional literacy coefficient of -0.164 then means that each increase of one functional functional variable value will cause an increase in culinary skill value of -0.164 with the assumption that other variables remain The coefficient of problem solving is 0.687 , it means that each increase of one value of problem solving variable will cause an increase culinary expertise score of 0.318 assuming other variables remain.

The value of functional literacy significance of $0.580>$ alpha 0.05 , it means functional literacy has no effect on culinary skills. Value of problem solving significance of $0.000<$ alpha 0,05 , it means problem solving effect on culinary skill

\section{B. Discussions}

The implementation of field work practices in SMK is done so that students learn in real terms in the world of work, dealinTg directly with consumers, interacting with other individuals within the work team. This is reinforced opinion This combination leads to direct alignment and the application of theory in practice. In addition, the dual VET program enables strong corporate responsibility for VETs that ensure labor market orientation of the skills acquired [5]. Eating is a primary need according to Maslow's hierarchy. This is in line with the knowledge and the concept of "Gastronomy serves as a study that produces that in this 21 st century the fulfillment of dietary needs not only provides physiological needs but also psychological and sociological needs and is also a process that directly affects physical and mental health if eating needs Not fulfilled [6].

The need and desire to meet the diverse cultures of culinary customers grows and requires new technical skills such as food management, procurement, segregation and preparation, as well as generic skills [7] Vocational education as proposed [8] has the objective of developing a work competency consisting of six specific outcomes: (1) routine expertise / routine skills: domains of working procedures, (2) resourcefulness, knowledge and talent for effective thinking ( 3 ) functional literacies / functional literacy: adequate mastery of digital letters, numbers and literacy, (4) craftsmanship/best work: pride, and attention to work, (5) business like attitudes/business attitudes: understanding the economic and social side From work, and (6) wider skills for growth: have a curious and resilient attitude toward continuous improvement through selflearning. Meanwhile, according to 8 vocational education develop vocational expertise / vocational skills or vocational skills is the main thing. At least the vocational expertise developed is: 1) develoving literacy, 2) developing 
numeracy, 3) developing information literacy, 4) developing problem solving skills, 5) developing problem solving skills, Developing creativity, and 6) working value.

\section{A. Functional Literacy Skills}

Generic skills consist of literacy/literacy, numeracy, and technical skills [7]. The acquisition of technical skills such as cooking requires functional literacy skills, but for certain individuals it is also necessary to follow the practice directly. Cooking classes play an important role in the acquisition of knowledge among individuals with insufficient literacy while self-directed teaching through cookbooks is more common in highly educated individuals [9]. Food literacy has emerged as a term to describe the daily practices associated with the consumption of healthy foods. The term is increasingly used in public policy, research and practice; However, there is no shared understanding of its meaning. The purpose of this study was to develop a definition of food security informed by its component identification. This is considered from two perspectives: food experts who aim to reflect the intent of existing policies and investments, and individuals, who can be considered experts in the practical practice of daily food consumption[9].

While the "official" definition for food literacy is not presented in the literature, it can be defined as the ability to make healthy food choices by having the skills and knowledge necessary to purchase, nutritional food for growth, and cooking food with implications for improving health. Food and cooking skills / food preparation are important for several reasons related to health, knowledge, empowerment, involvement, culture, food security, and fun. An engaging cooking skills program that targets young people to build self-efficacy, food knowledge and reading skills, self-confidence, and self-esteem, while potentially raising social health determinants. Furthermore, " food literacy " as a term is increasingly used in policy practice. In some cases the term 'food literacy' is used explicitly, on the other hand implied with the availability, skills, knowledge, and behavior of food. Implied components vary widely and include the language of food, knowledge of its origin, neophilia, food preparation and sustainability[9]

\section{B. Solution to problem}

The World Health Organization (WHO) by [6] identifies five basic areas of life skills applicable across cultures: (a) decision making and problem solving; (b) creative thinking and critical thinking; (c) communication and interpersonal skills; (d) Self-awareness and empathy, and (e) overcoming emotions and stress. The problem-solving skills as part of life skills are intended to facilitate the development of the psychosocial skills needed to meet the demands and challenges of everyday life, including in culinary skills.

Culinary Arts is one of the areas of Vocational Education and Technical Training (TVET) where students need to Have real-world problem-solving skills in addition to basic knowledge, techniques and hands-on cooking skills in order to survive in the industry. Problem-solving skills are highly sought after by employers but previous research has shown that TVET students do not have problem solving skills[10]. The PISA Assessment Framework 2003: Mathematics, Reading,
Knowledge and Problem Solving Knowledge and Skills (OECD, 2003) defines problem solving competencies as follows: ... one's ability to use cognitive processes to deal with and resolve real interdisciplinary situations where the solution path Is not immediately apparent and where the area of content or curricular area that may apply is not within a single subject area of mathematics, science or reading[4]

Collaborative problem solving (CPS) is an important and necessary skill used in education and manpower. While problem-solving as defined in PISA 201215 relates to selfemployed individuals in solving problems where solution methods are not immediately known, in CPS, individuals combine their understanding and efforts and work together to solve this problem[10].

Recent curriculum and teaching reforms have focused on broader teaching and teaching $21 \mathrm{st}$ century skills assessment[11]. These skills include critical thinking skills, problem solving, self-management, information and communication (ICT), communication and collaboration[12].Collaboration and skills Communication is essential in 21 st century expertise and is described in a number of skills curriculum and 21st century assessment report[13]. Collaboration has different advantages over individual problem solving as it allows for: Effective division of labor, Merging information from different perspectives, experiences and sources of knowledge[13]. ? Increased creativity and quality of solutions stimulated by the ideas of other group members[14].

\section{Culinary Expertise}

Employees who have knowledge, abilities, and expertise, is key, profitable, and competitive as it enables the establishment of superior value for customers and employee turnover[15]. Trained employees satisfy customers. Good service quality will most likely increase customer visits coming repeatedly in product or service purchases[14]. The concept of expertise is "the ability to do something better than others start according to the stated provisions, doing something well is a social construct. First, relative skills to others are regarded as experts if one can do things better than others. Second, is determined by how individuals in various groups judge as experts. Expertise can refer to all levels of society (eg, work or business in general life, plumbers, gardeners, public speakers or cyclists). Expertise refers to all jobs such as lawyers, mechanics or politicians. Focus on one or more of the different characteristics of expertise depending on culture (modern or traditional), setting (work environment or school), and time (eg during an economic crisis[8].

\section{CONCLUSION AND SUGGESTIONS}

Being a culinary expert needs to have adequate functional literacy including recipe reading (ingredients, processing techniques, portions, and prices), basic culinary concepts (preparation, cooking techniques, tool knowledge, processing knowledge, menu knowledge, K3 
and sanitation hygiene); interpretation of presentation (knowledge of presentation, appearance, texture, temperature and time of presentation). It also needs to have sufficient problem-solving skills as part of the life skills of developing the psychosocial skills needed to meet the demands and challenges of everyday life, including in culinary skills.

\section{ACKNOWLEDGMENT}

Acknowledgment authors convey to the Vocational Culinary School in Malang Raya who have worked together for the implementation of research. Furthermore, thanks to the authors also convey to the counselors who always give advice and input for improvement

\section{REFERENCES}

[1] “SK Spektrum PMK 2016.pdf.pdf." .

[2] Cedefop, From education ro working life. The labour market outcomes af vocational education and training. 2012.

[3] G. Rowley, K. Purcell, M. Richardson, R. Shackleton, S. Howe, and P. Whiteley, "Employers Skill Survey: Case Study Hospitality Sector," 2000.

[4] C. M. Sporre, I. M. Jonsson, and M. P. Ekström, "The Five Aspects Meal Model , FAMM From Michelin Guide to public meal sector," Conf. Proceedings, Int. Conreference Culin. Arts Sci. VIII, pp. 188-197, 2013.

[5] Y. J. Fandiño Parra, "21st Century Skills and the English Foreign Language Classroom: A Call for More Awareness in Colombia," Gist Educ. Learn. Res. J., vol. 7, no. 7, pp. 190-208, 2013.
[6] K. Hodge, S. Danish, and J. Martin, "Developing a conceptual framework for life skills interventions," Couns. Psychol., vol. 41, no. 8, pp. 1125-1152, 2013.

[7] J. Whatley, "Evaluation of a Team Project Based Learning Module for Developing Employability Skills Pedagogical Assumptions," vol. 9, 2012.

[8] J. Stevenson, “Developing Vocational Expertise," p. 289, 2003.

[9] OECD, Literacy, Numeracy and Problem Solving in TechnologyRich Environments. Framework for the OECD Survey of Adult Skills. 2012.

[10] "Pisa 2015 Collaborative Problem-Solving Framework," no. July, pp. 1-94, 2017.

[11] National Education Association, "Preparing 21st Century Students for a Global Society: An Educator' s Guide to the 'Four Cs ,"' pp. 1-38, 2014.

[12] U. Techanamurthy, N. Alias, and D. Dewitt, "Problem-solving skills in TVET: Current practices among culinary arts instructors in community colleges in Malaysia," Turkish Online J. Educ. Technol., vol. 2015, no. May, pp. 467-475, 2015.

[13] K. C. Tsai, "Leadership Recipes for Promoting Students' Creativity," Int. J. Humanit. Soc. Sci., vol. 3, no. 5, pp. 1-9, 2013.

[14] J. A. Wolfson, S. Frattaroli, S. N. Bleich, K. Clegg, and S. P. Teret, "Perspectives on learning to cook and public support for cooking education policies in the United States: A mixed methods study," Appetite, vol. 108, pp. 226-237, 2017.

[15] Y. Kim, S. S. Kim, J. Seo, and J. Hyun, "Hotel Employees' Competencies and Qualifications Required According to Hotel Divisions," J. Tour. Hosp. Culin. Arts, vol. 3, no. 2, pp. 1-18, 2011. 